\title{
Lung volume reduction for emphysema and the Canadian Lung Volume Reduction Surgery (CLVR) Project
}

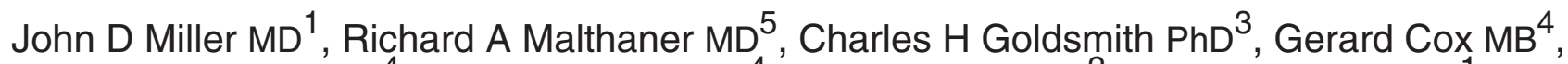
David Higgins $\mathrm{MD}^{4}$, David Stubbing $\mathrm{MD}^{4}$, Allan Kitching $\mathrm{MD}^{2}$, Toni E Newman $\mathrm{BA}^{1}$, Ellen McDonald RN ${ }^{1}$

${ }^{1}$ Division of Thoracic Surgery, ${ }^{2}$ Cardiology and ${ }^{3}$ Department of Biostatistics, McMaster

University; ${ }^{4}$ Firestone Regional Chest and Allergy Unit, St Joseph's Hospital, Hamilton; and ${ }^{5}$ Division of Thoracic Surgery, The University of Western Ontario, London, Ontario

JD Miller, RA Malthaner, CH Goldsmith, et al. Lung volume reduction for emphysema and The Canadian Lung Volume Reduction (CLVR) Surgery Project. Can Respir J 1999;6(1):26-32.

OBJECTIVE: To review the literature on the surgical treatment of emphysema and to present preliminary results from a pilot study of lung volume reduction (LVR) surgery.

DESIGN: Case series of consecutive patients referred for LVR surgery. Outcomes were quality of life, pulmonary function and exercise capacity.

SETTING: Two university-affiliated hospitals in Ontario. POPULATION STUDIED: Patients between the ages of 40 and 75 years with emphysema who had severe airflow limitation, hyperinflation of the lungs and impaired quality of life.

INTERVENTION: Bilateral reductions with multiple wedge resections of the lung using a linear stapling device with bovine pericardial buttressing were completed via a median sternotomy.

MAIN RESULTS: Of 50 patients referred, 24 underwent LVR surgery. Mean age of the cohort was 63 years. Opera- tive 30-day or in hospital mortality was $8 \%$. Two other patients $(8 \%)$ died from respiratory failure after LVR within the first year. Postoperative complications included prolonged air leaks (six of 24), tracheobronchitis (five of 24), mechanical ventilation (four of 24) and pneumonia (three of 24). Mean length of stay was 18 days (median 12 days). At one year, there was a sustained decrease in total lung capacity from $133 \%$ to $123 \%$ predicted. There were improvements in forced expiratory volume in $1 \mathrm{~s}$, from $22 \%$ of predicted preoperatively to $32 \%$ postoperatively, and in 6 min walk performance, from 345 to $381 \mathrm{~m}$. Improvements were also noted in the quality of life assessments.

CONCLUSIONS: Preliminary results suggest that LVR surgery is feasible and may improve the patient's quality of life, pulmonary function and exercise capacity. A randomized clinical trial comparing LVR plus the best medical management with the best medical management alone is currently underway to determine the effectiveness of LVR.

Key Words: Emphysema, Lung volume reduction surgery, Quality of life

Pour le résumé, voir page 27

Funded in part by the Ontario Thoracic Society, Toronto, Ontario, Autosuture Company Canada, St Laurent, Quebec and Bio-Vascular Inc, St Paul, Minnesota

Correspondence and reprints: Dr John Miller, Department of Surgery, St Joseph's Hospital, 50 Charlton Avenue East, Hamilton, Ontario L8N 4A6. Telephone 905-521-6126, fax 905-521-6156, e-mail jmiller@fhs.mcmaster.ca 


\section{La chirurgie de réduction de volume pulmonaire pour l'emphysème et le projet canadien de chirurgie de réduction de volume pulmonaire (CRVP)}

OBJECTIF : Passer en revue la littérature sur le traitement chirurgical de l'emphysème et présenter les résultats préliminaires d'une étude pilote sur la chirurgie de réduction de volume pulmonaire .

MODÈLE : Séries de cas de patients consécutifs adressés pour une CRVP. Les mesures des résultats portaient sur la qualité de vie, la fonction pulmonaire et la tolérance à l'exercice.

CONTEXTE : Deux hôpitaux affiliés à une université, en Ontario. POPULATION ÉTUDIÉE : Des patients âgés entre 40 et 75 ans atteints d'emphysème et présentant une obstruction bronchique sévère, une hyperinflation pulmonaire et une altération de leur qualité de vie.

INTERVENTION : Des réductions bilatérales avec des résections cunéiformes multiples du poumon au moyen d'un appareil d'agrafage linéaire avec soutien péricardique bovin ont été pratiquées par le biais d'une sternotomie médiane.

PRINCIPAUX RÉSULTATS : Des 50 patients adressés, 24 ont subi une CRVP. L'âge moyen de la cohorte était de 63 ans. La mortalité trente jours après l'opération ou à l'hôpital était de $8 \%$. Deux autres patients $(8 \%)$ sont décédés d'une insuffisance respiratoire dans la première année suivant la CRVP. Les complications postopératoires comprenaient des fuites d'air prolongées (six sur 24), des trachéobronchites (cinq sur 24), la ventilation mécanique (quatre sur 24) et des pneumonies (trois sur 24). La durée moyenne du séjour hospitalier était de 18 jours (médiane de 12 jours). À un an, on a noté une diminution soutenue de la capacité pulmonaire totale de $133 \%$ à $123 \%$ de la valeur théorique. Le volume expiratoire maximal/seconde (VEMS) s'est amélioré en passant de $22 \%$ de la valeur théorique avant l'opération à $32 \%$ après l'opération, ainsi que le périmètre de l'épreuve de marche de 6 min qui est passé de 354 m à $381 \mathrm{~m}$. Des améliorations ont également été observées dans les évaluations sur la qualité de vie.

CONCLUSIONS : Ces résultats préliminaires laissent à penser que la CRVP est réalisable et peut améliorer la qualité de vie du patient, sa fonction pulmonaire et sa tolérance à l'exercice. Un essai clinique randomisé comparant la CRVP associée à une prise en charge médicale optimale, avec seulement une prise en charge médicale optimale, est actuellement en cours pour déterminer l'efficacité de la CRVP.
$\mathrm{C}$ hronic obstructive pulmonary disease is a significant burden to Canadian society. Lung volume reduction (LVR) surgery has been shown in nonrandomized studies to improve functional and physiological parameters in patients with emphysema. Quality of life may also be improved. In Canada, interest in LVR surgery is increasing as the awareness of its potential benefits is being disseminated by doctors and the news media. The Medical Research Council (MRC) of Canada has recently funded a randomized, multicentred clinical trial to assess the effectiveness of LVR surgery, with specific attention to quality of life outcomes.

\section{EMPHYSEMA}

Emphysema is a condition of the lung characterized by an increase in the normal size of air sacs distal to the terminal bronchioles, either from dilation of the alveoli or by destruction of their walls (1). Pulmonary emphysema is characterized by a loss of elastic recoil in lung tissues, marked hyperinflation and limited airflow. Emphysema is now the fourth leading cause of death in Canada, with an annual mortality of 18 deaths/100,000 population per year (2). Emphysema affects men twice as often as women, and the death rate has been increasing over the past two decades (2). Emphysema is almost always associated with a smoking history, although people with alpha- 1 antitrypsin deficiency are also at risk. Fletcher and Peto (3) observed an accelerated decline in pulmonary function of persons who smoke. Stopping smoking at any time in one's life will slow the deterioration of lung function to normal rates, but the damage from smoking will never be reversed. As pulmonary function decreases and particularly when symptoms cause disability (typically forced expiratory volume in $1 \mathrm{~s}\left[\mathrm{FEV}_{1}\right] 1.0 \mathrm{~L}$ or less), life expectancy is greatly reduced. Five-year survival for people with an $\mathrm{FEV}_{1}$ between 0.75 and $1.25 \mathrm{~L}$ is less than $60 \%$ (4).

\section{HISTORY OF LVR}

Over the past century, numerous operative procedures have been devised to help patients with shortness of breath, ostensively designed specifically to correct perceived physiological problems. Historically, procedures have included costochondrectomy (5), transverse sternotomy (6), thoracoplasty (7), phrenic nerve paralysis (8), needle aspiration with injection of sclerosing agents $(9,10)$, excision of bullae with local plication (11), large resections such as segmentectomy and lobectomy $(12)$, partial pleurectomy $(9,10)$, resection of the carotid body (13-15), anatomic parasympathetic denervation of the lung (16) and reinforcement of membranous portions of the trachea (17).

In the 1950s and 1960s, Brantigan and colleagues $(18,19)$ presented their idea of volume reduction surgery. In this series of high risk patients, the mortality rate was $20 \%$, and the operation was never widely accepted. In 1976, Delarue et al (20) reported a series of surgical interventions for patients with emphysema and dyspnea. They too had a $20 \%$ mortality rate, and enthusiasm for the surgery remained low.

In 1995, following the advent of improved perioperative management of patients (lessons learned from lung transplantation) as well as improved anesthetic techniques (thoracic epidural), Cooper et al (21) presented a series of 20 patients from St Louis with a mortality rate of less than $5 \%$. Surgical interest in volume reduction surgery has been increasing since that time. When volume reduction surgery is successful, it appears to provide improvements in pulmonary function and the patient's quality of life that are unattainable with medical management and rehabilitation. However, there have been no prospective randomized trials comparing surgical intervention with the medical management of dyspnea, and thus, no definitive statements can be made about the effectiveness of LVR surgery. Given the extraordinarily high placebo effect of surgery and despite the 
difficulty inherent in evaluating surgical interventions, a randomized clinical trial addressing the role of LVR is clearly warranted.

\section{WHY DO PATIENTS IMPROVE?}

There have been numerous hypotheses about the mechanism of improvement for patients who have undergone volume reduction surgery. Primarily, it is believed that by reducing the volume of the thorax and returning the ribs and diaphragm to a more functional position, patients are able to ventilate their lungs more effectively. Other possible mechanisms of improvement are better ventilation to perfusion matching by resecting targeted areas of a shunt (a perfused but not ventilated lung) and resecting dead space (ventilated but not perfused areas); improved elastic recoil of the lung providing increased traction on small airways, thereby increasing the cross-sectional calibre of distal airways; and improved cardiac function with improved venous return and reduced pulmonary hypertension.

\section{TREATMENT PROGRAMS}

The treatment of end-stage emphysema with dyspnea currently involves a team approach with consultants from respirology, respiratory rehabilitation and surgery. Medical management $(22,23)$ includes smoking cessation (24), pharmacotherapy (25), immunization (26) and oxygen therapy $(27,28)$. Rehabilitation includes exercise, education and psychosocial support (29), while surgical management includes bullectomy (30), volume reduction surgery (31) and lung transplantation $(32,33)$.

People who are suitable candidates for volume reduction surgery include those with hyperinflation, airflow obstruction secondary to emphysema and stability of their other medical conditions. Typically, pulmonary function testing reveals an $\mathrm{FEV}_{1}$ of $15 \%$ to $40 \%$ of predicted, with residual lung volumes $150 \%$ to $300 \%$ of predicted and total lung capacity greater than $120 \%$ predicted. Chest x-rays show the typical hyperinflation with flattened and sometimes inverted diaphragms, and a large retrosternal airspace. Computerized axial tomography (CAT) scans of the chest typically show diffuse small and large emphysematous bullae. Ventilation to perfusion scans are carried out to help localize the most affected areas in the lung. Typically, apical portions of the lung are both poorly ventilated and perfused, which are associated with obvious destruction on a CAT scan.

\section{LVR SURGERY}

Technique: Numerous surgical approaches to LVR are currently employed. The most common approach is through a median sternotomy allowing open reduction in the volume of both lungs. Multiple wedge resections of the lung are taken using a linear stapling device (GIA-90, Autosuture Company Canada) with bovine pericardial buttressing (34). Other approaches include unilateral thoracotomy or video thoracic surgery (35). Another technique employed in some centres $(36,37)$ involves the use of a laser to scar the surface of the lung instead of stapling and cutting. The results with this technique have not been as encouraging as those of the multiple wedge resection approach (38).

Procedure: For this study, bilateral LVR surgery using a median sternotomy was chosen. Prophylactic antibiotics $(1 \mathrm{~g}$ intravenous cefazolin or $1 \mathrm{~g}$ vancomycin) were given 30 mins before skin incision. A thoracic epidural catheter was inserted preoperatively, and pre-emptive analgesia was provided with rectal indomethacin $(100 \mathrm{mg})$. General anesthesia was induced with intravenous propafol $(2 \mathrm{mg} / \mathrm{kg})$ or sodium thiopental (3 to $5 \mathrm{mg} / \mathrm{kg}$ ) while avoiding nitrous oxide and minimizing systemic narcotics. A left-sided double-lumen endotracheal tube was used to provide single lung ventilation. A standard median sternotomy incision was made, and the more severely affected lung was completed first. Single lung ventilation was used on the contralateral side and the collapsed lung elevated with moist packs or saline placed posteriorly. The total lung volume was reduced by $20 \%$ to $30 \%$ by removing the most destroyed areas of the lung with linear staplers (Autosuture GIA-90). The staple line was buttressed with bovine pericardium to reduce postoperative air leaks (4). Efforts were made to maintain the normal shape and configuration of the lung. An apical parietal pleurectomy was performed in some patients to encourage pleurodesis and help reduce air leaks. The procedure was repeated on the other side. Each pleural space was drained using two chest tubes attached to an underwater seal.

Postoperative analgesia was provided by a mixture of $0.25 \%$ bupivacaine and fentanyl $20 \mu \mathrm{g} / \mathrm{mL}$ administered through the thoracic epidural and titrated as required. To prevent respiratory depression and help reduce the need for narcotics, rectal indomethacin suppositories were administered (100 mg every $12 \mathrm{~h}$ ). Misoprostol $200 \mu \mathrm{g}$ three times per day was given orally to prevent gastrointestinal ulcers while on indomethacin. Routine physiotherapy was initiated as early as possible after surgery.

\section{OUTCOMES}

In the treatment of chronic obstructive lung diseases such as emphysema, where the intent of the treatment is to provide palliation and not to cure, the assessment of outcomes related to patients' quality of life is critical. Traditionally, as seen in the previously reported case series (18-21), the outcomes that were assessed were limited to measures of impairment (eg, pulmonary function tests, blood gases) or measures of disability (eg, exercise capacity), with little attention paid to measures of quality of life. With the advent of a number of reliable and valid measurement instruments, the assessment of quality of life has become an important outcome to include in the evaluation of LVR surgery.

\section{THE RANDOMIZED CONTROLLED TRIAL: THE PILOT WORK}

A pilot study was conducted in preparation for the MRCfunded radomized clinical trial that addresses the question of the effectiveness of LVR surgery in improving quality of life for patients with emphysema compared with the best medical management. Consecutive patients, referred for LVR at two 
TABLE 1

Pre- and postoperative assessment of impairment of patients undergoing lung volume reduction surgery

\begin{tabular}{lcccc}
\hline & Baseline & Three months & Six months & 12 months \\
\hline $\begin{array}{l}\text { Forced expiratory volume in 1s } \\
\quad \% \text { predicted) }\end{array}$ & $22 \pm 7(24)$ & $34 \pm 13(21)$ & $34 \pm 14(17)$ & $41 \pm 13(20)$ \\
Total lung capacity (\% predicted) & $133 \pm 24(23)$ & $113 \pm 17(15)$ & $113 \pm 14(11)$ & $123 \pm 15(17)$ \\
Residual volume (\% predicted) & $258 \pm 56(15)$ & $193 \pm 49(11)$ & $195 \pm 54(10)$ & $176 \pm 52(17)$ \\
$\mathrm{PaCO}_{2}(\mathrm{mmHg})$ & $47 \pm 8(24)$ & $42 \pm 7(22)$ & $41 \pm 58(10)$ & $42 \pm 6(11)$ \\
$\mathrm{Home}$ oxygen & $46 \%(24)$ & $32 \%(22)$ & $22 \%(22)$ & $15 \%(20)$ \\
\hline
\end{tabular}

The data are presented as mean \pm SD. Data from all available patients at each time point are given. The number of observations reported is given in parenthesis ( $n$ )

university centres, in London and Hamilton, Ontario, were evaluated between December 1995 and March 1997.

To be considered for the surgery, candidates were required to have disabling dyspnea due to severe airflow obstruction and hyperinflation. In general, they met the following criteria, adopted from the published literature, which were used as guidelines for selection of patients for LVR surgery:

- impaired quality of life (Chronic Respiratory Diseases Questionnaire [CRQ]-dyspnea less than 5);

- age between 40 and 80 years;

- postbronchodilator $\mathrm{FEV}_{1}$ less than $40 \%$ predicted;

- total lung capacity greater than $120 \%$;

- residual volume greater than $200 \%$;

- commitment to be a non-smoker; and

- able to attend, or have recently completed, respiratory rehabilitation.

Identification of appropriate, rigid inclusion criteria has been a dynamic issue. For the MRC-funded trial, they have been modified based on the experience reported here, and particularly influenced by the authors' evolving understanding of the disease and the optimum perioperative care of these patients.

Patients were excluded if they had comorbid conditions precluding surgery, such as pulmonary hypertension (systolic pulmomary arterial pressure greater than $50 \mathrm{mmHg}$ or mean pulmomary arterial pressure greater than $30 \mathrm{mmHg}$ as determined by right heart catheterization, performed if screening echocaradiography indicated raised right ventricular pressures), excessive steroid dependence (greater than $10 \mathrm{mg} /$ day), malnutrition, obesity or chronic bronchitis (excessive sputum production of more than $25 \mathrm{~mL} /$ day). Hypercapnea $\left(\mathrm{PaCO}_{2}\right.$ greater than $55 \mathrm{mmHg}$ ) was considered to place the candidate at an increased risk but was not an absolute exclusion criterion.

All patients were assessed by a consultant respirologist and underwent respiratory rehabilitation if indicated. Once their well-being had been optimized and rehabilitation was completed, they underwent bilateral LVR surgery using a median sternotomy.

Impairment, disability and handicap were assessed before and after the procedure. All patients underwent sternotomy with bilateral wedge resections. Impairment was assessed by changes in pulmonary function testing and arterial blood gases. Disability was assessed by the 6 min walk test, and handicap was assessed by a portfolio of three validated health-related quality of life instruments - CRQ (39); Medical Outcomes Study Short Form Health Survey (MOS SF36) (39-41) and Health Utilities Index (HUI) (42-45).

\section{RESULTS}

Fifty patients were assessed, 24 of whom were eligible for surgery. Mean age of the cohort was $62.8 \pm 7.5$ (years \pm SD) with a male to female ratio of 17:7. Baseline data were obtained after the completion of a respiratory rehabilitation program. Early in-hospital mortality was $8 \%$ (two of 24), and two other patients died within one year of surgery as a result of respiratory failure and pneumonia. Postoperative data are presented for testing at three, six and 12 months after surgery on patients who were able to complete the follow-up. Significant in-hospital complications included prolonged air leak (more than 10 days) in six of 24 cases (25\%), tracheo-

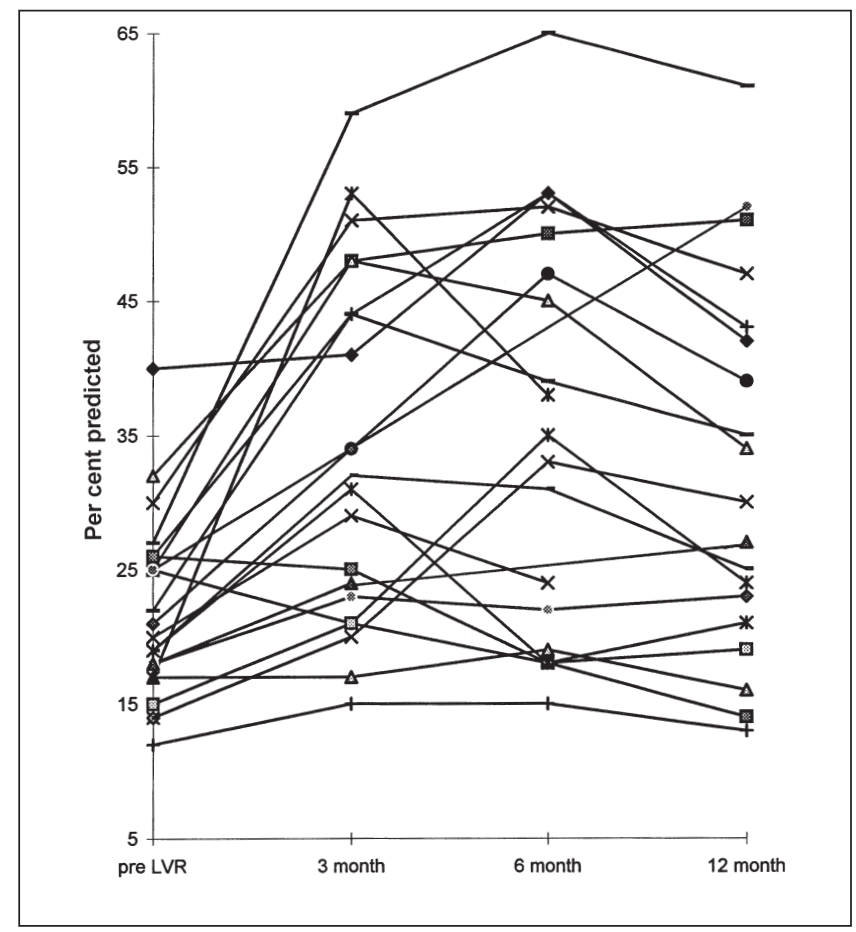

Figure 1) The post-bronchodilator, forced expiratory volume in $1 \mathrm{~s}$ $\left(F E V_{l}\right)$ is shown for individual patients who were available for follow-up over one year after they underwent lung volume reduction (LVR) surgery. Spirometry was performed at three, six, and 12 months. Data are presented as percentage predicted for 24 indivudal patients who were able to perform pulmonary function testing. Summary data are presented in Table 1. 


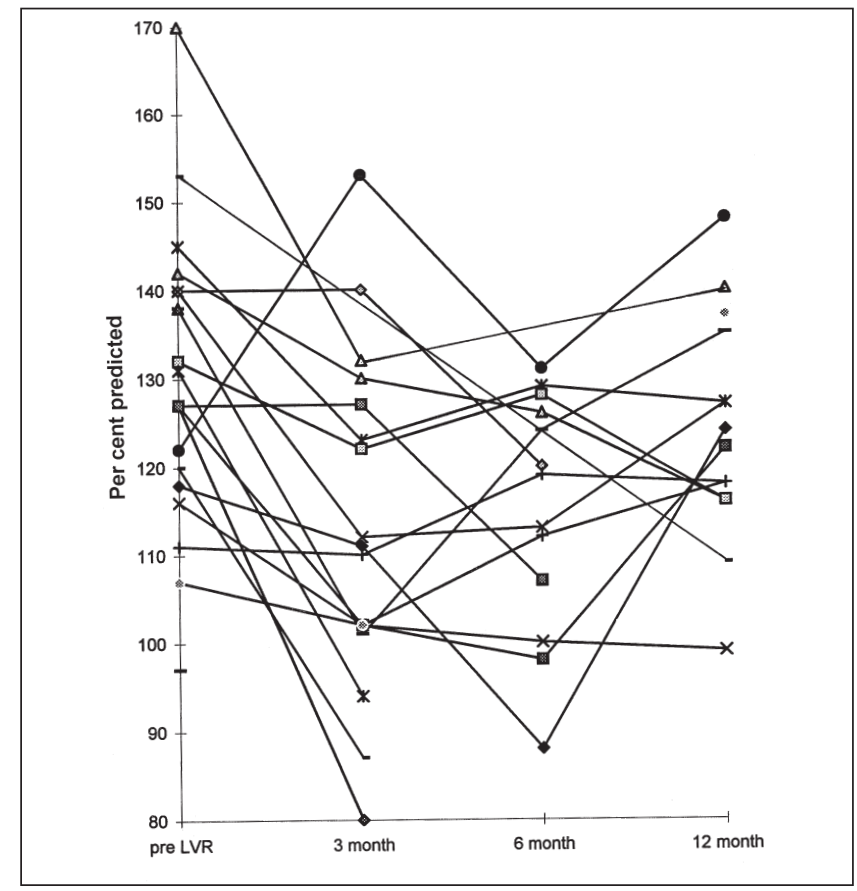

Figure 2) Total lung capacity was measured after patients had completed respiratory rehabilitation and had their respiratory health optimized before lung volume reduction (LVR) surgery. Repeat measurements were made at three, six and 12 months following surgery. Data are presented as percentage predicted for 22 individuals who were able to perform pulmonary function testing (three patients are represented by single data points). Summary data are presented in Table 1

bronchitis in five of $24(21 \%)$, need for mechanical ventilation in four of $24(17 \%)$, panic attacks in three of $24(13 \%)$ and pneumonia in three of $24(13 \%)$. No patient underwent reoperation. Mean length of stay in intensive care unit was 4.7 days, with a median stay of two days. The mean length of hospital stay (LOS) was $18.3 \pm 18.5$ days, with a median stay of 12 days. Seventy-five per cent of the cohort had a LOS of less than 18 days.

At one year following LVR surgery, $84 \%$ of the cohort were alive. $\mathrm{FEV}_{1}$ had increased from $22 \%$ of predicted preoperatively to $32 \%$ postoperatively (Table 1 , Figure 1). There was an expected decrease in lung volumes, with total lung capacity demonstrating a mean decrease from $133 \%$ to $123 \%(\mathrm{P}=0.02)$ and residual volume demonstrating a decrease from $258 \%$ to $176 \%$ (Figures 2,3 ). There was no significant change in mean $\mathrm{PaO}_{2}$, although half the patients who required oxygen preoperatively no longer required oxygen following LVR surgery (Table 1). The mean arterial $\mathrm{PaCO}_{2}$ was reduced from $47 \mathrm{mmHg}$ to $42 \mathrm{mmHg}$ after surgery. The distance walked in 6 mins (6 min walk test) increased from 345 to $381 \mathrm{~m}$, and exercise capacity (stage 1 exercise test) improved from $328 \mathrm{kpm} / \mathrm{min}$ to $625 \mathrm{kpm} / \mathrm{min}$, although the number of patients who completed this latter test was small (Figures 4,5).

Two of the three quality of life measures demonstrated improvement for patients at 12 months' follow-up; the CRQ dyspnea scores improved from a mean of 3.1 to a mean of 5.2,

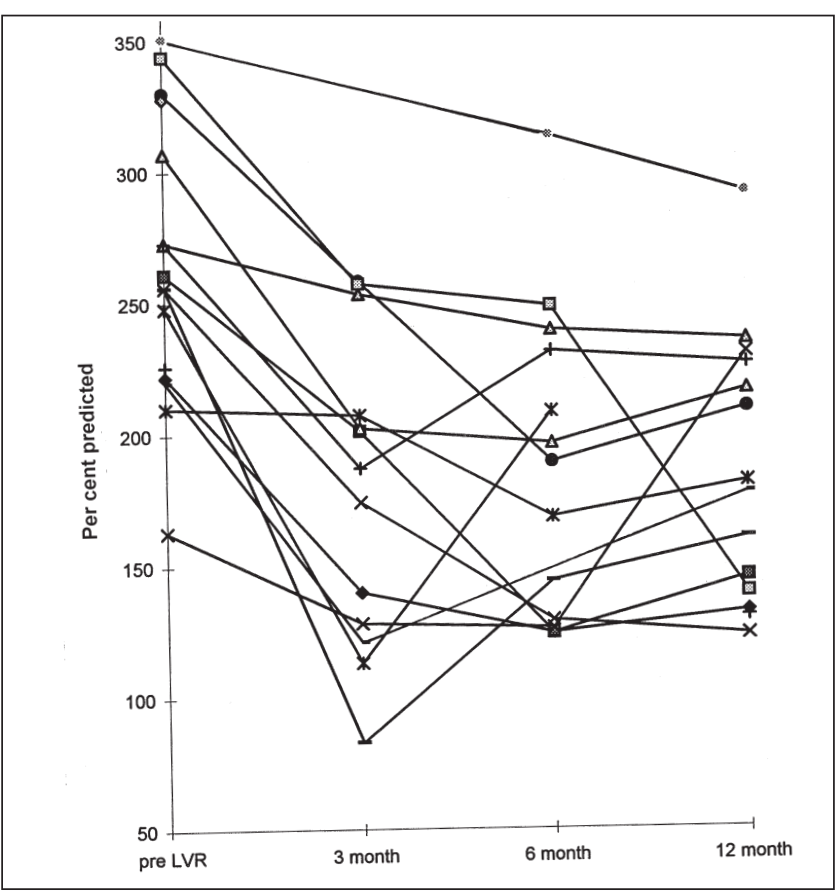

Figure 3) Residual volume is reported as percentage of predicted. Data for 18 patients are given (three patients are represented by single data points). Measurements were made before surgery and after three, six and 12 months of follow-up. Residual volume is reduced by lung volume reduction (LVR) surgery, while total lung capacity is minimally lower. These changes are reflected in increased vital capacity. Summary data are presented in Table 1

and the SF-36 general health scores improved from a mean of 41 to a mean of 62 (Table 2). The third quality of life measure, the HUI, showed trends to improvement in early follow-up assessments, but did not show improvement in health utility at one year. This reflects an important measurement capacity of the HUI because the outcome for all patients, including nonsurvivors, is captured and reported. Unlike other measurement instruments, the HUI assigns a score of zero to patients who do not survive. This allows for all patients to be included in the analysis of follow-up data and prevents errors that might arise from assessing and reporting outcomes only in survivors.

These changes represent a magnitude of improvement that may be unparalleled by any medical treatment for advanced emphysema. The encouraging results from this case series indicate that it is feasible to perform this procedure in appropriate settings that have the necessary supporting services, including anesthesia, physiotherapy and rehabilitation. This experience with patients with more advanced disease than thos who are included in recently published series has provided the impetus for a nation-wide MRC-funded randomized controlled trial. Ten major university centres in Canada have joined to evaluate lung volume reduction surgery in a prospective randomized trial. An enrolment of 350 patients over five years in this study is anticipated; this study will compare the best medical management including rehabilitation with the best medical management plus surgery. 


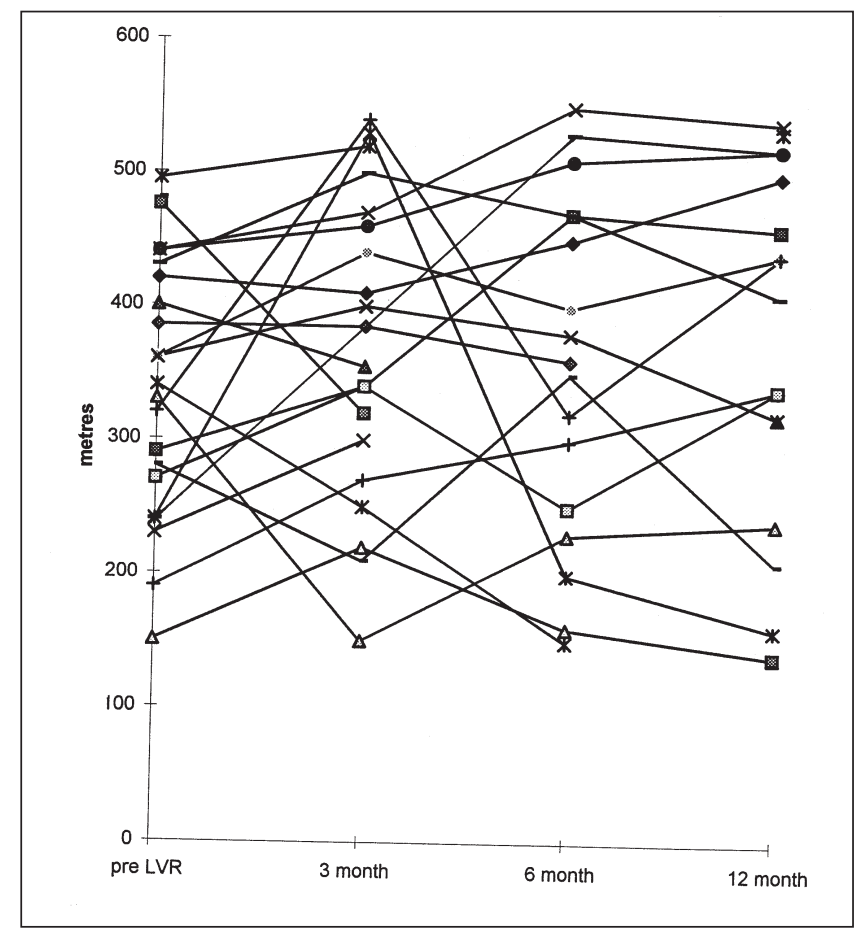

Figure 4) The distance, in metres, walked in 6 mins was assessed before surgery and at three, six and 12 month intervals during the first year after lung volume reduction (LVR) surgery. Complete data are reported for 24 patients for whom there is data (three patients are represented by single data points). There is modest improvement in the mean distance walked, when assessed three months and longer after surgery

\section{COMMENT}

LVR appears to provide meaningful physiological changes that reduce a patient's dyspnea and improve his or her quality of life. It also appears to be safe and feasible in Canada. It remains to be demonstrated whether LVR surgery can withstand the rigors of a randomized, controlled trial compared with optimal medical management. We look forward to the results of the Canadian LVR Surgery (CLVR) Project.

For further information about the CLVR trial, or about referring suitable patients to the trial, please contact Dr J Miller, co-principal investigator by telephone 905-521-6126, fax 905-521-6156 or email jmiller@fhs.mcmaster.ca or Ms T Newman, trial coordinator by telephone 905-522-1155 ext 5092, fax 905-521-6156 or e-mail newmant@fhs.mcmaster.ca. Further information about the trial can also be obtained by visiting the CLVR website at <www.clvr.org $>$.

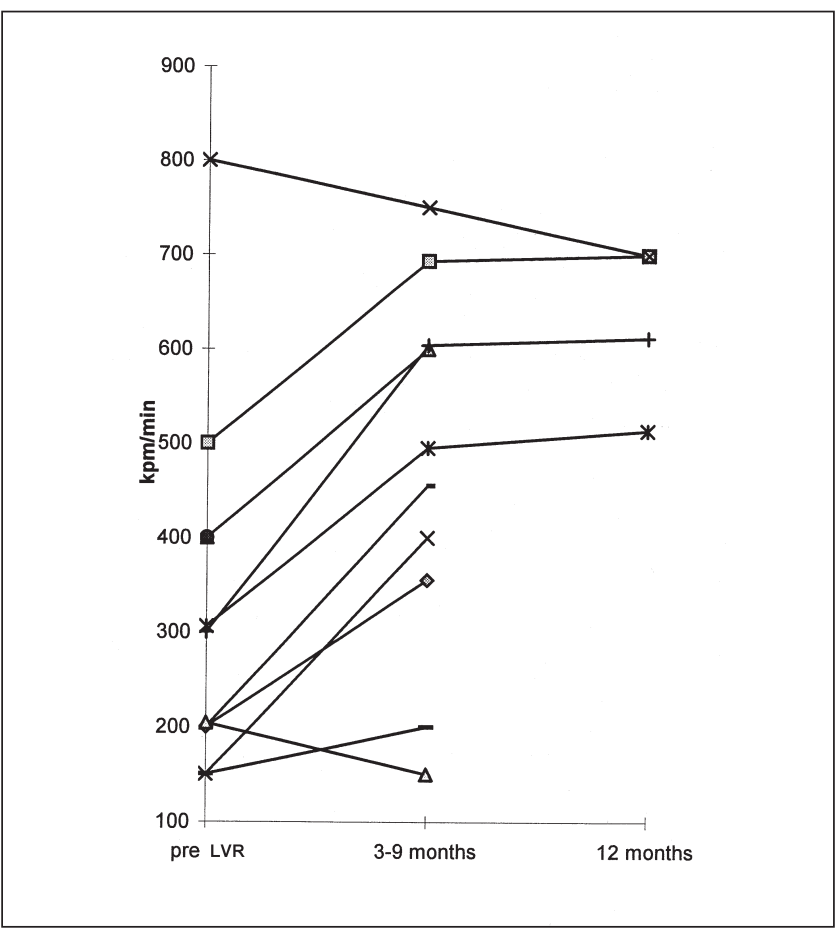

Figure 5) Exercise capacity was measured by stage 1 exercise testing using a cycle ergometer. Complete data are available on only four patients. Individual results of testing in 10 patients are shown. These results that indicate exercise capacity improved following surgery in the majority (eight of 10) of patients

\section{REFERENCES}

1. Dorlands Illustrated Medical Dictionary, 28th edn. Philadelphia: WB Saunders \& Company, 1994.

2. The Lung Association of Ontario, 1995.

3. Fletcher CM, Peto R. The natural history of chronic airflow obstruction. Br Med J 1977;i:1645-8.

4. Diener CV, Burrows B. Further observations on the course and prognosis of chronic obstructive lung disease. Am Rev Respir Dis 1975;111:719-24.

5. Freund WA. Zur operativen Behandlung gewisser Lungkrankheiten inbesondere des auf starrer Thoraxdilation beruhenden alveolar5en Emphysems Z Exp Path Therap 1906;3:479-98.

6. Phillips EW, Scott WJM. The surgical treatment of bronchial asthma. Arch Surg 1920;19:1425-56.

7. Gaensler EA, Cugell DW, Lindgren I, Verstraeten JM, Smith SS, Strieder JW. The role of pulmonary insufficiency in mortality and invalidism following surgery for pulmonary tuberculosis. J Thorac Surg 1955;29:163-87.

8. Knudson RJ, Gaensler EA. Surgery for emphysema. Ann Thorac Surg 1965;1:332-62.

TABLE 2

Pre- and postoperative assessments of handicap of patients undergoing lung volume reduction surgery

\begin{tabular}{lcccc}
\hline & Baseline & Three months & Six months & 12 months \\
\hline $\begin{array}{l}\text { Chronic Respiratory Diseases } \\
\text { Questionnaire (CRQ)-dyspnea }\end{array}$ & $3.1 \pm 1.3(12)$ & $4.6 \pm 1.4(11)$ & $4.7 \pm 1.5(9)$ & $5.2 \pm 1.3(11)$ \\
$\begin{array}{l}\text { Medical Outcomes Study Short } \\
\quad \begin{array}{l}\text { Form Health Survey } \\
\text { (MOS SF-36) general health }\end{array}\end{array}$ & $41(7)$ & $66(9)$ & $69(8)$ & $62(11)$ \\
Health Utilities Index & $0.58 \pm 0.26(23)$ & $0.59 \pm 0.27(21)$ & $0.61 \pm 0.29(17)$ & $0.54 \pm 0.34(14)$ \\
\hline
\end{tabular}

A change of more than 1 (scale 1 to 7) on the CRQ represents a clinically significant difference. In the MOS SF-36, 0 is worst and 100 is best. In the Health Utility Index, 0 is dead and 1 is the state of perfect health. A change of 0.05 would represent a clinically significant difference on this index 
9. Crenshaw GL, Rowles DF. Surgical management of pulmonary emphysema. J Thorac Surg 1952;24:398.

10. Dugan DJ, Hardy KL. Pulmonary air cysts - a therapeutic concept. Am J Surg 1955;89:1023.

11. Nissen R. A conservative operation of air cysts of the lung. Rocky Mountain Med J 1945;42:282.

12. Eloesser L. Congenital cystic disease of the lung. Surg Gynecol Obstet 1931:52:747

13. Nakayama K. Surgical removal of the carotid body for bronchial asthma. Dis Chest 1961;40:595.

14. Overholt RH. Glomectomy for asthma. New York J Med 1963;63:3372.

15. Overholt RH. Glomectomy for asthma. Dis Chest 1961;40:605-10.

16. Rienhoff WM, Gray LN. Treatment of intractable bronchial asthma by bilateral resection of posterior pulmonary plexus. Arch Surg 1938;37:456-69.

17. Herzog H. Erschlaffung und expiratorische Invagination der membranosen Teile der intrathorakalen Luftrohre und der Hauptbronchienn als Ursach der asphyktischen Anfalle beim Asthma bronchiale und bei der chronischen asthmoiden bronchitis des lungenemphysems. Schweiz Med Wschr 1954;84:217-21.

18. Brantigan, OC, Mueller E, Kress MB. A surgical approach to pulmonary emphysema. Am Rev Respir Dis 1959;80:194-206.

19. Brantigan OC. Pulmonary emphysema. Surg Gynecol Obstet 1961;112:117-9.

20. Delarue NC, Woolf CR, Sander DE, et al. Surgical treatment for pulmonary emphysema. Can J Surg 1977;20:222-31.

21. Cooper JD, Trulock EP, Triantafillou AN, et al. Bilateral pneumectomy (volume reduction) for chronic obstructive pulmonary disease. $\mathrm{J}$ Thorac Cardiovasc Surg 1995;109:106-19.

22. American Thoracic Society. Comprehensive outpatient management of COPD. Am J Respir Crit Care Med 1995;152:S84-95.

23. Canadian Thoracic Society Working Group. Guidelines for the assessment and management of chronic obstructive pulmonary disease. Can Med Assoc J 1992;147:420-8.

24. Anthonisen NR, Connett JE, Kiley JP, et al. Effects of smoking intervention and the use of an anticholinergic bronchodilator on the rate of decline of FEV1. The Lung Health Study. JAMA 1994;272:1497-505.

25. Anthonisen NR, Manfreda J, Wallen CPW, et al. Antibiotic therapy in exacerbations of chronic obstructive pulmonary disease. Ann Intern Med 1987;106:196-204.

26. Fedson D. Influenza and pneumococcal vaccination in the elderly: Newer vaccines and prospects for clinical benefits at the margin. Prevent Med 1994;23:751-5.

27. Nocturnal Oxygen Therapy Group. Continuous or nocturnal oxygen in hypoxic chronic obstructive lung disease. Ann Intern Med 1980;93:391-8.

28. Medical Research Council Working Party. Long term domicilary oxygen in chronic hypoxic cor pulmonale complicating chronic bronchitis and emphysema. Lancet 1981;i:681-5.

29. Goldstein RS, Gort EH, Stubbing D, Avendano MA, Guyatt GH Randomized controlled trial of respiratory rehabilitation. Lancet 1994;344:1394-7.

30. Naclerio E, Langer L. Pulmonary cysts: Special reference to surgical treatment of emphysematous blebs and bullae. Surgery 1947;22:516.

31. Gaissert HA, Trulock EP, Cooper JD, Sundaresan RS, Patterson GA. Comparison of early functional results after volume reduction or lung transplantation for chronic obstructive pulmonary disease. J Thorac Cardiovasc Surg 1996;111:296-307.

32. Patterson GA, Maurer JR, Williams TJ, et al. Comparison of outcomes of double and single lung transplantation for obstructive lung disease. J Thorac Cardiovasc Surg 1991;101:623-32.

33. Briffa NP, Dennis C, Higenbottam T, et al. Single lung transplantation for end stage emphysema. Thorax 1995;50:562-4.

34. Cooper JD. Technique to reduce air leaks after resection of emphysematous lung. Ann Thorac Surg 1994;57:1038-9.

35. Keenan RJ, Landreneau RJ, Sciurba FC, et al. Unilateral thoracoscopic surgical approach for diffuse emphysema. J Thorac Cardiovasc Surg 1996;111:303-16.

36. Wakabayashi A, Kayaleh R, Barker SJ, et al. Thoracoscopic carbon dioxide laser treatment of bullous emphysema. Lancet 1991;337:881-3.

37. Wakabayashi A. Thoracoscopic laser pneumonoplasty in the treatment of diffuse bullous emphysema. Ann Thorac Surg 1995;60:936-42.

38. McKenna FJ, Brenner M, Gleb AF, et al. A randomized trial of stapled lung reduction versus laser bullectomy for diffuse emphysema. J Thorac Cardiovasc Surg 1996;111:317-22.

39. McHorney CA, Ware JE, Rogers W, et al. The validity and relative precision of MOS short and long form health status scales and Dartmouth COOP charts: Results from the Medical Outcomes Study. Med Care 1992;30:MS253-65.

40. Hayes V, Morris J, Wolfe C, Morgan M. The SF-36 questionnaire: is it suitable for use with older adults? Age Ageing 1995;24:120-5.

41. Mahler DA, Mackowiak JI. Evaluation of the Short Form 36-Item questionnaire to measure health-related quality of life in patients with COPD. Chest 1995;107:1585-9.

42. Furlong W, Torrance GW, Feeny D. Properties of Health Utility Index: preliminary evidence. Qual Life Newsl 1996;13/14:3-10.

43. Feeny D, Furlong W, Boyle M, Torrance GW. Multi-attribute health status classification systems: Health Utilities Index. PharmacoEconomics 1995; 7:490-502.

44. Torrance GW, Feeny DH, Furlong WJ, Barr RD, Zhang Y, Wang Q Multiattribute utility function for a comprehensive health status classification system. Health Utilities Index Mark 2. Med Care 1996;34:702-22.

45. Boyle MH, Furlong W, Feeny D, Torrance G, Hatcher J. Reliability of the Health Utilities Index-Mark III used in the 1991 cycle 6 general Social Survey Health Questionnaire. Qual Life Res 1995;4:249-57. 


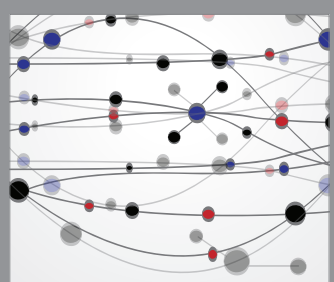

The Scientific World Journal
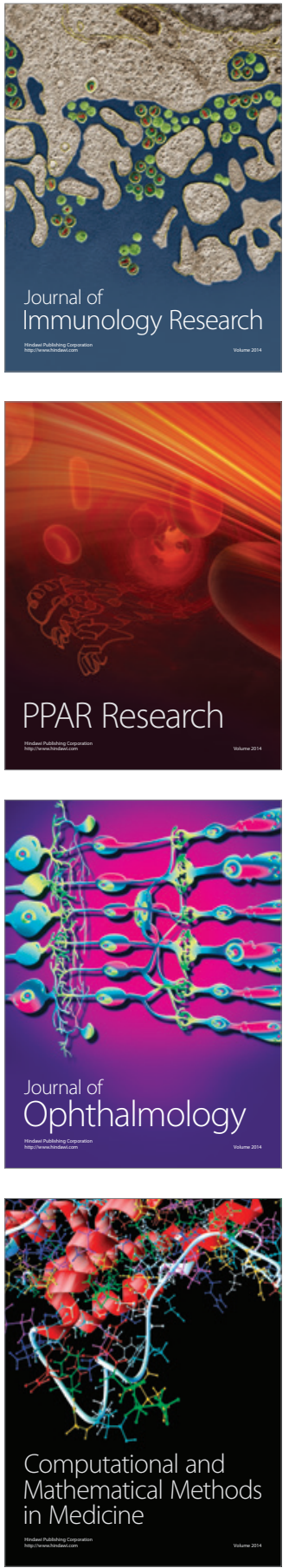

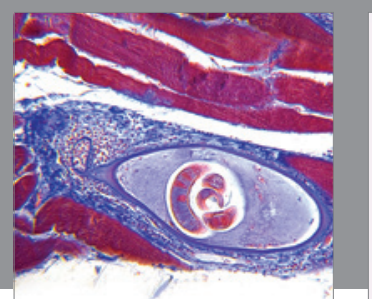

Gastroenterology Research and Practice

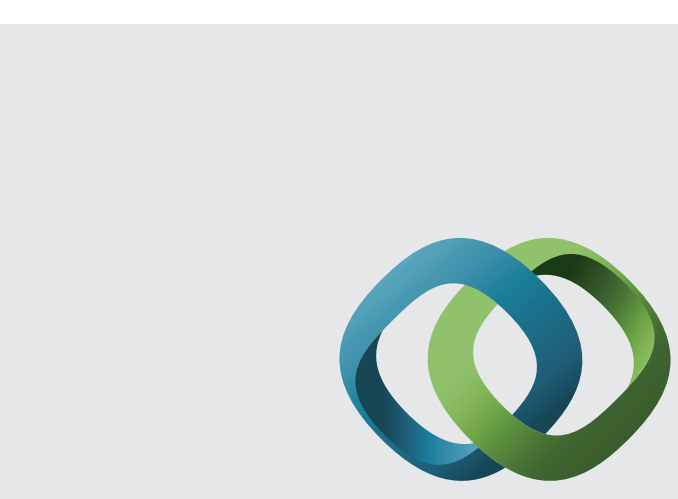

\section{Hindawi}

Submit your manuscripts at

http://www.hindawi.com
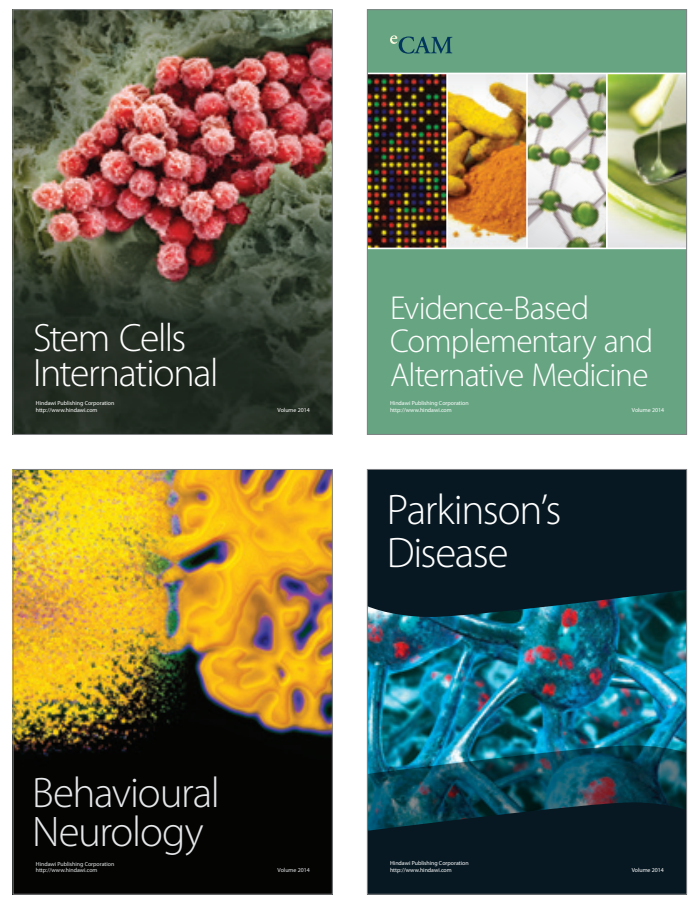
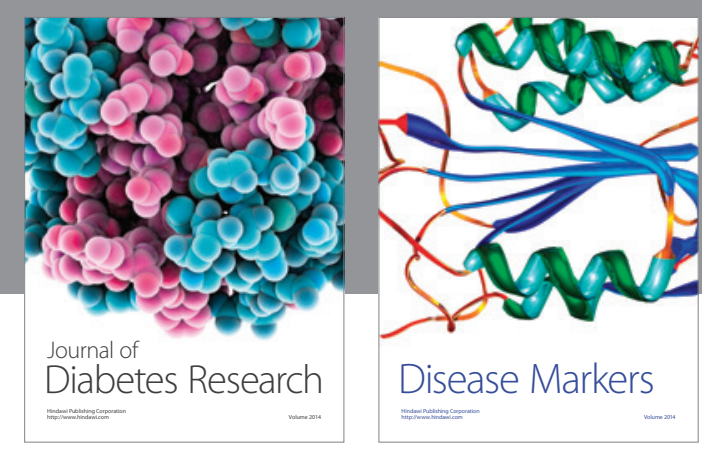

Disease Markers
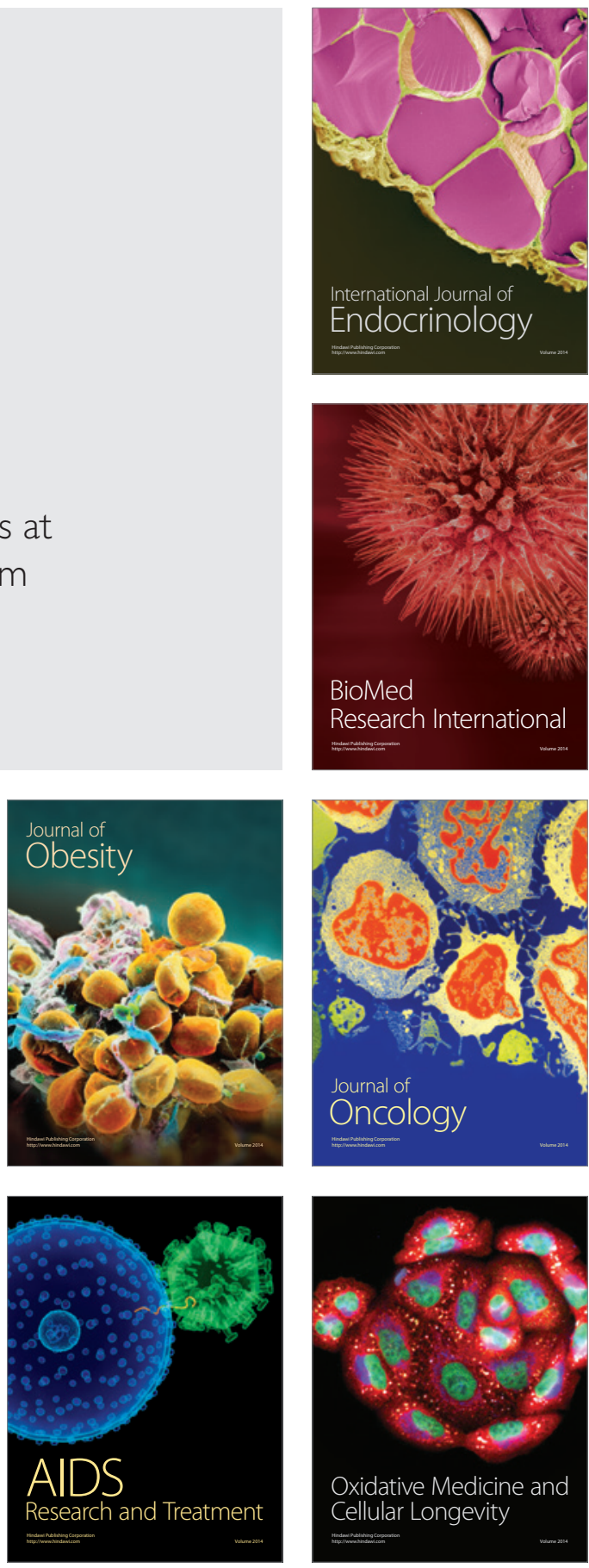